\title{
The pricing of convertible bonds in the presence of structured conversion clauses: the case of Cashes
}

\author{
Marida Bertocchi*, Vittorio Moriggia and Sebastiano Vitali \\ Department of Management, Economics and Quantitative Methods, \\ University of Bergamo, \\ Via dei Caniana 2, 24127, Bergamo, Italy \\ Email: marida.bertocchi@unibg.it \\ Email: vittorio.moriggia@unibg.it \\ Email: sebastiano.vitali@unibg.it \\ *Corresponding author
}

\section{Costanza Torricelli}

Department of Economics "Marco Biagi", University of Modena and Reggio Emilia, Viale Berengario 51, 41100, Modena, Italy

Email: costanza.torricelli@unimore.it

\begin{abstract}
The aim of this paper is to analyse the pricing of highly structured convertible bonds by taking a real world case. To this end we examine the Cashes (Convertible And Subordinated Hybrid Equity-linked Securities), which are characterized by both voluntary and mandatory conversion that depend on different triggering events, as well as floating coupons whose payment hinges on dividends and earning of the issuer. Our results highlight that prices are very sensitive to the modelling of the sources of uncertainty, both market and credit risk, and underscore the relevance of the time horizon chosen for the estimation.
\end{abstract}

Keywords: convertible bond; structured clauses; uncertainty modelling.

Biographical notes: Marida Bertocchi is professor of applied mathematics in economics and finance at the University of Bergamo. She taught numerous courses at the Universities of Bergamo, Urbino and Milan, including basic and advanced calculus, portfolio theory, advanced mathematical finance, stochastic optimization and parallel processing. Bertocchi has been dean of the Faculty of Economics and Business Administration and Director of the Department of Mathematics, Statistics, Computer Science and Applications at the University of Bergamo. She is the scientific coordinator of the PhD program in Economics, Applied Mathematics and Operational Research. She is author of numerous publications on bond portfolio management, and economic and financial applications. She was referee and reviewer in the EEC Vth and VIth framework. 
She has been responsible for many grants from national and international sources as well as from private firms.

Vittorio Moriggia is Associate Professor in Computer Science for Finance and in MATLAB for Finance at the University of Bergamo. He holds a Ph.D. in Computational Methods for Financial and Economic Forecasting and Decisions from the University of Bergamo. He taught Mathematic Models for Financial Markets, Financial Engineering, Computer Science both at the University of Bergamo and in professional courses granted by public and private institutions. He implemented several models in different languages for research and production. He is author of various papers and books on Stochastic Programming models applied to Finance and on Computer Science. His research and teaching interests are in the areas of Financial Derivatives, Logical Analysis of Data, Programming Languages and Stochastic Programming.

Costanza Torricelli is professor of Quantitative Methods and Finance at the University of Modena and Reggio Emilia, where she is Affiliate to the Centre on Banking and Finance, and Affiliate to the Centre for Research on Pensions (University of Torino). She has a degree in Business Economics (University of Modena), an M.Phil. in Economics (University of Warwick), and a Ph.D. in Economics (University of Bologna). She taught courses at undergraduate, graduate and $\mathrm{PhD}$ levels in Quantitative Methods, Finance, and Risk Management in Italy, UK, and Germany. Her research topics are related to derivatives, financial market efficiency, credit risk and financial stability, and household finance. She has been head of research of many funded research projects, referee of international journals and research grants, member of the Scientific Committee of various international conference, and author of many scientific publications in economics and finance.

Sebastiano Vitali is going to discuss the final dissertation of his $\mathrm{PhD}$ in Economics, Applied Mathematics and Operational Research in December 2015 at University of Bergamo. He already won a post-doc position at the same University. He presented results at several international conferences and workshops. His research interest are in the area of Derivatives, Asset and Liability Management, Insurance and Pension Funds, Stochastic Programming and its applications in Finance.

\section{Introduction}


Convertible bonds are corporate bonds with an additional optional feature. Most commonly they are callable, i.e. they give the bondholder the right but not the obligation to convert the bond into a specified number of shares of common stock at specified times prior to maturity. Hence they share characteristics with both common stocks and straight bonds, and their pricing is not straightforward being dependent on many sources of risks (equity, interest rate and credit). However, they allow for a great variety of structures according to the optional feature (callable on the stock rather than puttable on the bond), the conversion period, and additional clauses, thus resulting attractive for both issuer and institutional investors. ${ }^{1}$

Specifically, the inclusion of structured conversion clauses gave rise to the Contingent convertible bonds, also known as "CoCos", which are bonds mandatorily convertible into common stock in a certain prescribed circumstance, called the triggering event.

This automatic conversion in stocks made this type of convertibles particularly attractive after the 2008 financial crisis, especially from a regulatory point of view, ${ }^{2}$ and this explains the number of issuances that took place between 2009 and 2011 (e.g. by Credit Suisse, Lloyds, Rabobank, Unicredit). With respect to convertible bonds, the pricing of CoCos is made more troublesome by the mandatory contingent conversion clause and the literature is still rather limited.

Against this backdrop, the aim of this paper is to investigate the pricing issue of CoCos, in the presence of a high level of product structuring, in order to highlight the sensitivity of the final outcome to the modelling assumption. To this end, we take the case of particular CoCos, the Unicredit Cashes, which are highly structured products. In

\footnotetext{
${ }^{1}$ For details on terminology and possible structures, as well as issuer and investor motivations, see Ramirez (2011).

${ }^{2}$ We refer to bank capital regulation and the consultative documents that led the regulation known as Basel 2.5 (BCBS, 2011a) and Basel 3 (BCBS, 2011b), whereby CoCo bonds are loss absorbing, and can be qualified for inclusion in Basel 3-compliant Tier 1 capital.
} 
fact they are characterized by both voluntary and mandatory conversions that depend on different triggering events, as well as floating coupons whose payment hinges on dividends and earning of the issuer. Given the absence of official quotes for this type of bonds, the relevance of our result is apparent.

The paper is structured as follows. In the Section 2, we review the relatively scant literature on CoCos pricing. While in Section 3 we illustrate the features of the CoCos priced in this paper, the Unicredit Cashes, in Section 4 we present the modelling assumption and in Section 5 we comment upon the results obtained. Last Section concludes.

\section{The literature}

Given the manifold features of CoCos and the variety of risk involved, it is not surprising that the models used to price them differ according to the prevalent viewpoint taken. Three are the main modelling approaches put forward in the theoretical literature.

The Structural model was proposed with the aim to price those CoCos where the trigger is connected to a capital ratio. This feature naturally calls for a stochastic modelling of the assets and liabilities of the institution, that represents the underlying, coupled with some contingent clause of capital conversion into equity when the capital-to-assets trigger is touched. In line with Merton-type models for credit risk, bankruptcy occurs when the value of the institution's assets drops below the value of its liabilities. Among the few models falling within this approach, the closer to real world CoCos is Pennacchi (2011) where the asset-liability dynamics of a bank is modelled as a stochastic process with jumps. The main drawback of the structural approach is the need to simplify assumptions, in particular as far as the conversion factor is concerned.

The Equity Model rests on the theory of stock pricing in that it considers the underlying stock price as the main driver of CoCos' evaluation. De 
Spiegeleer and Schoutens $(2011,2012)$ show that in its simplest form a CoCo bond is replicable as the sum of straight bond (which serves to price the bond component) and a knock-in forward (which prices the conversion right), minus a series of down-and-in binary options (which serve to cancel the coupon after conversion if this happens). It follows that the price can be determined as the algebraic sum of these three components. If this approach has the great advantage of offering a closed form pricing formula, it is applicable only to simple structures.

The Credit derivative model rests on the consideration that the conversion of the CoCos is essentially connected with financial difficulties of the reference institution, which is often a bank. Hence, the price of this type of instruments depends on the bank default probability whose (instantaneous) process is to be modelled. A non-negligible drawback of this approach is that it hardly incorporates the coupon that would have been paid after conversion.

As for the empirical literature, which is still quite limited, most interestingly Wilkens and Bethke (2014) propose a comparative empirical evaluation of the three models on two real CoCos, issued by Lloyds Banking Group and Credit Suisse. They conclude in favour of the Equity model, although the performance of the three models is very similar in terms of fitting. It has to be stressed however that, both in terms of maturity and product structure, neither of the two CoCos considered by the authors is as complicated as the Unicredit Cashes, and this explains their favour for the Equity model.

To sum up, most of the cases considered in the literature could be defined as "simple" CoCos and this motivates the present study, which addresses the problem of pricing a very long maturity and highly structured CoCos such as the Cashes.

\section{Description of Cashes}


Cashes stands for Convertible and Subordinated Hybrid Equity-linked Securities. While referring to Ramirez (2011) for an all-round description of the whole transaction inclusive of institutional details, in this Section we recall only the features of Cashes, which are relevant for pricing. Specifically:

1) Issue date: $23^{\text {rd }}$ February 2009

2) Notional amount: EUR 2.983 billion (EUR 1,000,000)

3) Depository bank: Mediobanca

4) Coupon: paid quarterly in arrears, at a variable rate of Euribor 3months plus 450 basis points (Interest Amount)

5) Conditions for coupon payment ${ }^{3}$ : if for the preceding financial year

a) cash dividends are distributed in relation to Unicredit shares and

b) in the Unicredit consolidated financial statements shows profits for an amount bigger that the dividends paid

6) Dividend protection: bond holders would receive pro-rata any amount exceeding a Unicredit dividend yield of $8 \%$, to be calculated on the basis of the price of the shares recorded during the 30 business days preceding approval of the financial statements (Additional Amount)

7) Maturity date $15^{\text {th }}$ December 2050

8) Redemption: not in cash but in Unicredit stocks

9) Conversion price: EUR 3.083, equal to the ratio of the notional amount to the underlying shares underwritten by Mediobanca

10) Voluntary conversion: exercise of the right by the bond holder at any time starting at least 40 days from the issue date

11) Automatic conversion upon the occurrence of the following events (triggering events):

a) Following the seventh year after issue, the market price of

Unicredit's common stock exceeded $150 \%$ of the conversion price

\footnotetext{
${ }^{3}$ The coupon is not cumulative, i.e. any amount not paid, either in full or in part, for any given period is no longer due in any subsequent period
} 
Title

(i.e., EUR 4.625, subject to any adjustments) for at least 20 days during any given period of 30 consecutive days

b) Unicredit's aggregate, consolidated or stand-alone capital requirement fell below 5\% (or any other threshold set out in the applicable supervisory legislation for the purpose of absorbing losses in innovative capital instruments)

c) Unicredit breaches any of its payment obligations undertaken pursuant to the usufruct contract, is declared insolvent or in liquidation

d) Mediobanca is declared insolvent or in liquidation

e) Maturity is reached.

To be noted that in 2011 Unicredit carried out a reverse stock split of ordinary and savings shares based on a ratio of 1 new ordinary or savings share for every 10 existing ordinary or savings shares. It follows that some quantities relevant for pricing are now obtained multiplying the original ones by ten. Specifically the conversion price is now EUR 30.83 so that the triggering event sub a) corresponds to a stock price of EUR 46.20.

To say it with Ramirez (2011) “...Cashes have characteristics of both perpetual bonds and mandatory convertibles, being treated as debt by the tax authorities and as equity by the banking regulators. The bond holders only have a pledge on the underlying shares and can opt to convert their bonds for a fixed number of shares." (cf. page 128).

With respect with the few CoCos that are priced in the literature, see e.g. Wilkens and Bethke (2014), Cashes presents additional complications, which make its pricing an interesting exercise. First, it was issued with a very long maturity (about 41 years) and still has a long time to maturity; second, the payment of the floating coupons is conditional on specific circumstances (see conditions sub 5 above), and automatic conversion is conditional on a multi-variate trigger, i.e. a combination of accounting, market and regulatory trigger events (see conditions sub 11 above). 
Author

\section{The pricing of Cashes}

As highlighted in the previous section, Cashes are highly structured convertibles so that for their pricing we cannot rely on either of the three approaches recalled in Section 2. On the one hand, we cannot use the closed formulas provided by the Equity approach as they are appropriate to more simple structures; on the other hand, the Structural models would require too many simplifying assumptions, while the Credit derivative model does not allow to easily account for the coupon lot after conversion.

Thus we have to rely on numerical procedures based on models describing the sources of uncertainties. Specifically, we have to consider and to model the following sources of uncertainty: the equity return, the interest rate process, the default event, the dividend payout.

Once the sources of uncertainty are modeled, we can build scenarios along which we will be able to evaluate the Cashes.

\section{Historical data windows}

The analysis involves a historical window starting from $1^{\text {st }}$ January 1999 until $13^{\text {th }}$ March 2015. We perform the pricing on $13^{\text {th }}$ March 2015. We use, as input data for determining the model coefficients estimations, the daily adjusted closing price of the Unicredit's stock and the daily Euribor 3-month rate. In order to highlight the impact of the recent crisis on the price estimate, we divide the period in two parts: before and after the end of 2008. Then, we consider a pre-crisis estimation from $1^{\text {st }}$ January 1999 to $31^{\text {st }}$ December 2008 (PRE case) and a post-crisis estimation from $1^{\text {st }}$ January 2009 to $13^{\text {th }}$ March 2015 (POST case). We also develop an analysis considering the whole period (ALL case). 


\section{Risk free rate}

In order to compute the actual value of the cash flows generated on the scenarios by the Cashes, we adopt as risk free rate the ECB rate. Then, the discount rate is supposed to be deterministic. The ECB yield curve uses the Svensson model (see Svensson, 1994) to generate the spot rate for each Term To Maturity (TTM). This methodology is a parametric model given by the following formula

$$
\begin{aligned}
z(T T M)=\beta_{0} & +\beta_{1}\left[\frac{1-e^{\left(\frac{-T T M}{\tau_{1}}\right)}}{\frac{T T M}{\tau_{1}}}\right]+\beta_{2}\left[\frac{1-e^{\left(\frac{-T T M}{\tau_{1}}\right)}}{\frac{T T M}{\tau_{1}}}-e^{\left(\frac{-T T M}{\tau_{1}}\right)}\right] \\
& +\beta_{3}\left[\frac{1-e^{\left(\frac{-T T M}{\tau_{2}}\right)}}{\frac{T T M}{\tau_{2}}}-e^{\left(\frac{-T T M}{\tau_{2}}\right)}\right]
\end{aligned}
$$

where $\beta_{i}$ and $\tau_{j}$ are parameters estimated by ECB. We consider the parameters on $13^{\text {th }}$ March 2015, as reported in Tab. 1.

Table 1. Parameters for the Svensson yield curve model

The model produces the yield curve shown in Fig. 1.

Figure 1. ECB yield curve computed with the Svensson model

\subsection{Modeling the sources of uncertainty}

In order to model each source of risk, we evaluated possible modeling alternatives and we took a decision based essentially on two criteria. On 
the one hand, we evaluated the capability of each assumption to appropriately represent the data over the period considered, on the other we had to account for the complexity and maturity of the Cashes, which necessarily required simplifying assumptions. However, we mention the alternatives to each assumption taken and we explicitly motivate our choice.

\section{Equity return and short-term interest rate modeling}

As for the equity return, the decision is essentially between the mostly used Geometric Brownian Motion and more sophisticated models, such as regime switching or jump models. While the latter allow to consider the occurrence of possible worldwide financial crisis in the future, the former assumption is in line with most of the literature and suitable for long-term horizons.

Therefore we take the equity return modeled as a Geometric Brownian Motion of the classical form:

$$
\frac{d s_{t}}{s_{t}}=\mu d t+\sigma d Z_{t}
$$

where $\mu$ is the drift, $\sigma$ is the volatility of the equity return process and $Z_{t}$ is the standard Brownian motion.

As for the short-term interest rate, since we want to account for the possibility of mean-reversion and negative rates, the short-term interest rate is modeled as follows:

$$
d r_{t}=\alpha\left(\beta-r_{t}\right) d t+v r_{t}^{\gamma} d Z_{t}
$$

where $\alpha, \beta, \gamma, v$ are model parameter, $r_{t}$ is the short-term interest rate and $Z_{t}$ is the standard Brownian motion.

The choice in favor of Vašíček model is made not only on the grounds of its simplicity, but also because more sophisticated models, which are able to capture the whole dynamic of the short-term interest rate process, 
require nonnegative interest rates, a hypothesis that cannot be accepted over the period considered notoriously characterized by negative rates.

As proposed in Wilmott (1998), we assume that the innovations of the two processes (1) and (2) (log-return of stocks and interest rate return) follow a bivariate Normal distribution with fixed variance-covariance matrix. Moreover, in order to perform a risk neutral pricing, we adopt the risk free $\hat{\mu}$ as drift for the equity process and we include the dividend yield $q$. Thus, the stochastic equations become:

$$
\begin{gathered}
\frac{d s_{t}}{s_{t}}=(\hat{\mu}-q) d t+\sigma d Z_{t}^{1} \\
d r_{t}=\alpha\left(\beta-r_{t}\right) d t+v r_{t}^{\gamma} d Z_{t}^{2}
\end{gathered}
$$

and

$$
E\left[Z_{t}^{1} Z_{t}^{2}\right]=\rho d t
$$

The dividend yield is supposed to be constant. The risk free rate is the daily forward rate implicit in the ECB yield curve.

For the interest rate process, the parameters have been estimated by trying several methods for different models according to the choice of $\gamma$. Notice that for $\gamma=0$ we obtain the well-known Vašíček model that allows for negative interest rates. For $\gamma=1$, we obtain the Brennan-Schwartz model, see Brennan and Schwartz (1980), but in this case the estimation of the parameters produces unreasonable results and the scenario generation is not reliable too. The case $\gamma=\frac{1}{2}$ and in general the case $\gamma$ equal to a noninteger value cannot be investigated because of the presence of negative values of $r_{t}$ in our historical series. Among the possible special cases that derive from (4) by imposing restrictions on the model parameters, see Kramov (2013), we use the Vašíček model. We perform an Ordinary Least Squared (OLS) using a classical two-step approach consisting of a former estimation of $\alpha$ and $\beta$ and a latter estimation of $v$ from the residuals. Assuming that the process follows the Vašíček model we also assume to 
know the distribution of the observed values. Therefore, the Generalized Method of Moments (GMM) leads to the Maximum Likelihood Estimation (MLE), see James and Webber (2000). The MLE produces an estimation for all the parameters $(\alpha, \beta$ and $v)$ jointly. In Table 2 , for the three considered period cases, we report the estimated parameters of the Vašíček model and the statistics according to the equity return volatility and the correlation between short-term interest rate and equity process. Vašíček parameters are computed by both OLS and MLE obtaining the same values.

Table 2: Estimated parameters of the Vašíček model and statistics of the equity process

Figure 2. Euribor 3month historical series

Comparing the Euribor 3month historical series shown in Fig. 1 with the estimated Vašíček parameters, the value of the parameter $\beta$ (which represents the long-term equilibrium rate) is fully reasonable. In the ALL case and in the POST case the rate converges to the zero lower bound. In the PRE case the estimation finds an equilibrium rate of $2.5 \%$ both in the period 2003-2005 (when the rate is stable between 2\% and 2.5\%) and in the crisis period (when the rate fells from $5.4 \%$ on $7^{\text {th }}$ Oct 2008 , to $2.8 \%$ on $31^{\text {st }}$ Dec 2008).

To be sure that the Vašíček model does not become meaningless, we need to test that the value of $\alpha$ is significantly different from zero. For this purpose we perform the Likelihood test, as suggested in James and Webber (2000), in which the estimated parameters $\hat{\theta}$ are compared with the estimation performed with a set $m$ of restrictions which produces the parameters $\bar{\theta}$. Then, the distance between the values of the Likelihood 
functions follows a Chi-Squared distribution with $m$ degrees of freedom, i.e.

$$
\begin{gathered}
R=2 N(L(\hat{\theta})-L(\bar{\theta})) \\
R \sim \chi_{m}^{2}
\end{gathered}
$$

We test the value of $\alpha$ to be statistically different from zero by imposing the restriction $\alpha=0.0001$ and computing the Likelihood test. We cannot perform the test directly with $\alpha=0$ because in that case the Likelihood function is not defined by construction.

The observed values of the statistic $R$ are reported in Table 3 .

Table 3: Estimated parameter $\alpha$ of the Vašíček model and related Likelihood test statistics

In the three cases the null hypothesis, $\alpha=0$, is rejected. Therefore, the Vašíček model is statistically suitable to describe the short-term interest rate.

We also test for two simpler alternative estimations of the Euribor 3month rate which is used to compute the coupon payments. The first hypothesis is to extract the Euribor 3-month rate implicit in the ECB yield curve. Thus, in each coupon payment day, from the spot yield curve we calculate the forward rate to compute the cash flow. The second hypothesis considers a flat level of the Euribor 3-month rate, in particular a level of $0.10 \%$.

Default event modeling 
The alternatives here are either to assume a constant default probability or to estimate time varying default probabilities based on a multiperiod setting. Given the long maturity of the product considered, the many sources of risk, and the need to estimate credit riskiness of two institutions, we stick to the simplest assumption.

The default event is modeled considering a constant default probability, for each year from the pricing date till the maturity date for both the issuer (Unicredit) and the depository (Mediobanca) of the convertibles; we assume the two are independent from each other.

We extract the default probability, for both the issuer and the depository, from the Credit Default Swap contracts, namely Through The Cycle (TTC), and considering the default probability associated to a certain rating level, called Point In Time (PIT). Table 4 reports the default probability obtained.

Table 4. Estimated default probability on annual basis

\section{Dividend payout probability}

The dividend payout probability is supposed to be constant for the overall period and we consider two distinct scenarios of 0.90 (TTC) or 0.75 (PIT), corresponding to the probability of being paid. An evolution of the proposed model would be to introduce a correlation between the equity scenarios and the dividend payout and then produce scenarios also for the dividend payout event linking the probability with the equity returns.

\section{Results}

The pricing of the convertible is carried out creating a daily scenario tree

till the maturity of the convertible $\left(15^{\text {th }}\right.$ December 2050), i.e. 13000 days, 
for the correlated evolution of the equity prices and the Euribor 3-month rates. On each scenario, in each node, we evaluate the default event and the trigger conditions which may lead to an automatic conversion in stocks. In each node when the coupon payment occurs, we compute the coupon amount considering the Euribor 3-month rate and the dividend payout event. The nominal amount is fixed to EUR 1,000,000 rather than EUR 2.983 billion in order to make the results easier to interpret.

We generate a fan of 10000 daily scenarios for all the above mentioned stochastic parameters. Finally, we compute for each day the average cash flow over the 10000 scenarios and we discount these values with the ECB yield curve of $13^{\text {th }}$ March 2015 assumed to be the risk free rate curve.

All the computations are done on a HP490, IntelCore I7-4790, 3.60 GHz, RAM 16 GB with Windows 8.1 64bit. Computation time is around one minute.

The results are shown in Table 5. The value of the Cashes is relevantly sensible to the default probability hypothesis. Indeed the price is above par when we adopt the TTC default probability and it is below par when the PIT default probability is adopted. The flat Euribor 3-month framework (fixed at $0.1 \%$ ) produces a slightly lower price than the implicit Euribor 3months (implicit in the ECB yield curve).

Using the Vašíček model we obtain significantly different values according to the considered period (PRE, POST or ALL). The PRE estimates produce high price values. The POST and the ALL estimated parameters implicitly consider a view of long-term low coupon rates and then the price computed on low cash flows is lower than the PRE case. Moreover, the PRE case prices are almost the same as the ones obtained with the Euribor 3-month implicit assumption. This means that the ECB yield curve expectations are much more oriented to a PRE crisis framework of the yield structure rather than to a low coupon rates perspective. 
The dividend payment probability, which influences directly the payment of the coupons, affects linearly the Cashes price: a reduction of the probability from $90 \%$ to $75 \%$ produces a reduction around $15 \%$ in the price evaluation.

Table 5. Cashes estimated actual value (EUR)

\section{Conclusions}

In this paper we have investigated the pricing of a real highly structured contingent convertible bonds such as the Unicredit Cashes, which are characterized by: both voluntary and mandatory conversion that depend on different triggering events, as well as floating coupons whose payment hinges on dividends and earning of the issuer. It follows that none of the most popular models for pricing (Structural, Equity, and Credit derivative models) can be used, and we have to resort to scenario analysis to make the problem manageable.

Our results highlight that prices are very sensitive to the modelling of the sources of uncertainty, both market and credit risk. Specifically, the value of the Cashes strongly depends on the approach taken to estimate the default probability of Issuer and Depository. Indeed the price is above par when we adopt a long term view (TTC default probability) and it is below par when rely on current estimate (PIT default probability). As for the assumption on the Euribor, which determines the coupons, the flat Euribor 3-month framework (at $0.1 \%$ ) produces a slightly lower price than the implicit Euribor 3-months (implicit in the ECB yield curve). By estimating a model instead, i.e. Vašíček model, we obtain significantly different values according to the considered period for the estimation. Using only the period pre-2008 financial crisis, estimates produce high price values, which are much in line with those obtained with the Euribor 3-months implicit in the ECB yield curve. By taking either the whole period or the 
post crisis one, estimated parameters implicitly consider a view of longterm low rates and then the resulting price is lower than the other cases.

The dividend payment probability, which influences directly the payment of the coupons, affects linearly the price: a reduction of the probability from $90 \%$ to $75 \%$ produces a reduction around $15 \%$ in the price evaluation.

As far as we know, this is the first paper explicitly modelling the pricing of this convertible bond. Given the absence of official quotes for this type of bonds, the relevance of our result is apparent since it highlights not only the importance of motivating the modelling assumption, but also the relevance of the estimation window. The implications of a fair pricing of this bond are manifold, ranging from its marketability and liquidity, to accounting consequences. In fact, if these bonds were useful to financial institutions in the wake of the financial crisis, being loss absorbing and qualified for inclusion in regulatory capital, their presence in the bondholders' balance sheet makes a correct evaluation particularly relevant.

Further, we stress that the proposed scenario analysis lends itself to price other convertible bonds in the presence of very structured clauses, e.g. Floating Rate Equity-linked Subordinated Hybrid (FRESH) or Enhanced Capital Notes (ECN).

\section{References}

Brennan, M.J., and E.S. Schwartz, 1980, "Analyzing Convertible Bonds," Journal of Financial and Quantitative Analysis, XV (4), 907-929.

BCBS (Basel Committee on Banking Supervision), 2011a, "Revisions to the Basel II Market Risk Framework" (February). 
BCBS (Basel Committee on Banking Supervision), 2011b, "Basel III: A Global Regulatory Framework for More Resilient Banks and Banking Systems" (June).

De Spiegeleer, J. and Schoutens W., 2011, Contingent Convertible (CoCo) Notes: Structuring and Pricing. London: Euromoney Books.

De Spiegeleer, J. and Schoutens W., 2012, Pricing Contingent Convertibles: A Derivatives Approach, Journal of Derivatives, Volume 20, Number 2, 27-36.

James, J., and Webber, N., 2000. Interest rate modelling. WileyBlackwell Publishing Ltd.

Hull, J. C., 2015, Options, futures and other derivatives, Pearson, Prentice Hall, Milano, 9th Edition.

Khramov V., 2013, Estimating Parameters of Short-Term Real Interest Rate Models, IMF WP/13/212, 1-27.

Pennacchi, G., 2011, "A Structural Model of Contingent Bank Capital.” Working paper, University of Illinois (June).

Ramirez J., 2011, Handbook of Corporate Equity Derivatives and Equity Capital Markets, John Wiley \& Sons Ltd, Chichester.

Vašíček O., 1977, An equilibrium characterization of the term structure. Journal of Financial Economics, Volume 5, 177-188.

Wilkens S. and Bethke N., 2014, Contingent Convertible (CoCo) Bonds: A First Empirical Assessment of Selected Pricing Models, Financial Analysts Journal, Volume 70, Number 2, 59-77.

Wilmott P., 1998, Derivatives: The Theory and Practice of Financial Engineering, John Wiley \& Sons Ltd, Chichester. 
Figures

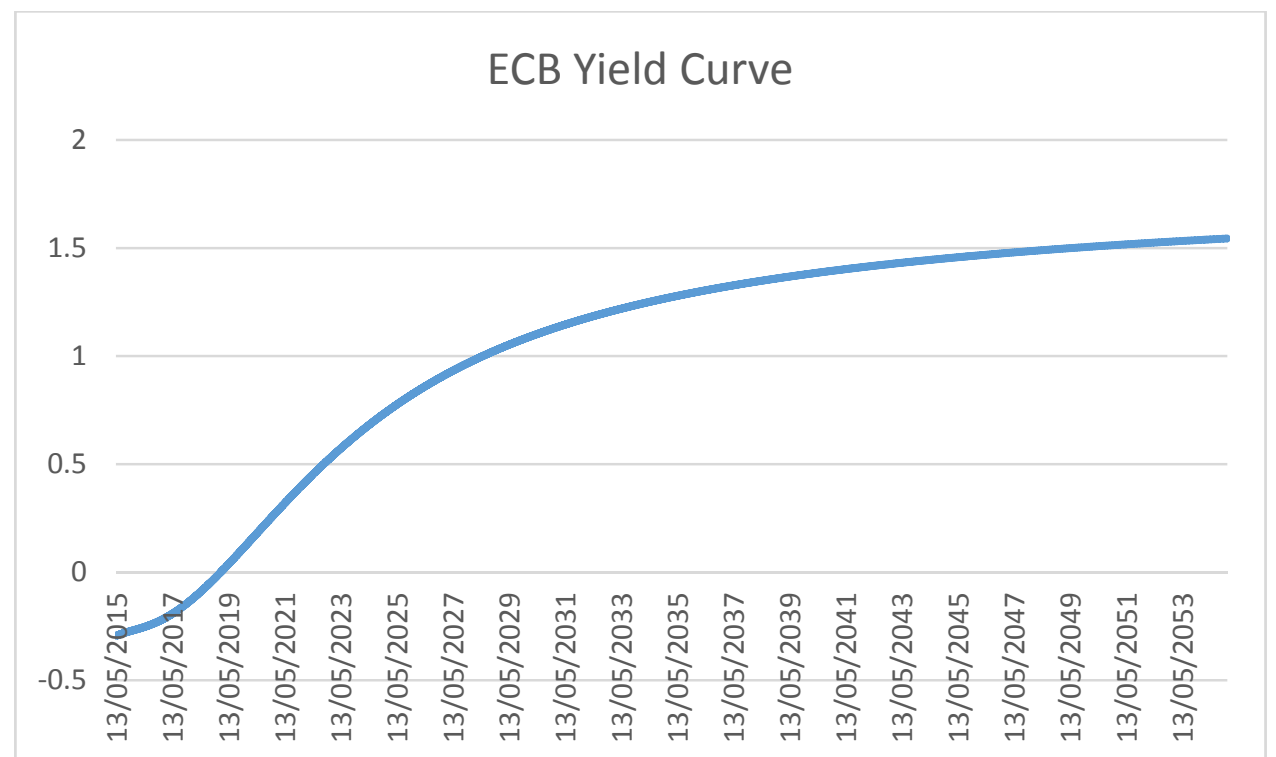

Figure 1. ECB yield curve computed with the Svensson model 
Author

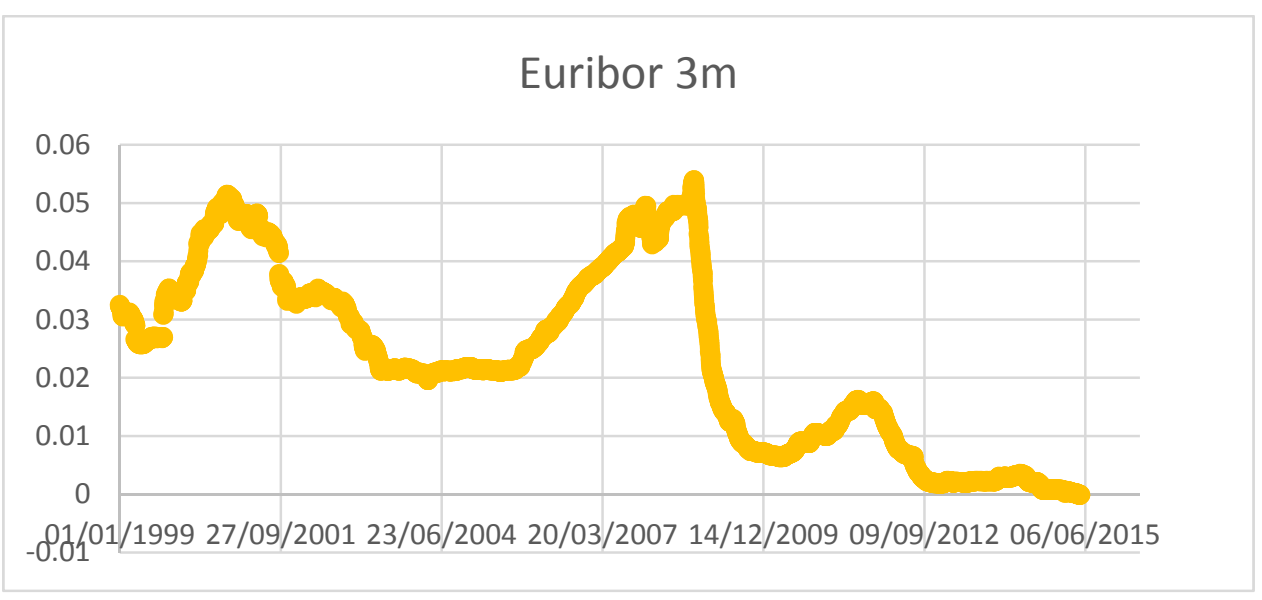

Figure 2. Euribor 3month historical series

\section{Tables}

\begin{tabular}{|c|c|}
\hline$\beta_{0}$ & 1.8150 \\
\hline$\beta_{1}$ & -2.1100 \\
\hline$\beta_{2}$ & 2.6979 \\
\hline$\beta_{3}$ & -6.1485 \\
\hline$\tau_{1}$ & 1.4244 \\
\hline$\tau_{2}$ & 1.8841 \\
\hline
\end{tabular}

Table 1. Parameters for the Svensson yield curve model 


\begin{tabular}{|c|c|l|l|l|}
\hline & & ALL & PRE & POST \\
& & $01 / 01 / 1999$ & $01 / 01 / 1999$ & $01 / 01 / 2009$ \\
& & $13 / 03 / 2015$ & $31 / 12 / 2008$ & $13 / 03 / 2015$ \\
\hline \multirow{2}{*}{ Vašíček parameters } & $\alpha$ & 0.066 & 0.065 & 1.634 \\
\cline { 2 - 5 } & $\beta$ & 0 & 0.025 & 0.003 \\
\cline { 2 - 5 } & $v$ & 0.0033 & 0.004 & 0.0016 \\
\hline $\begin{array}{c}\text { Equity return } \\
\text { volatility }\end{array}$ & $\sigma$ & 0.1543 & 0.1413 & 0.1620 \\
\hline Correlation & $\rho$ & 0.026 & 0.015 & 0.083 \\
\hline Dividend Yield & $q$ & \multicolumn{3}{|c}{0.0187} \\
\hline
\end{tabular}

Table 2: Estimated parameters of the Vašíček model and statistics of the

\begin{tabular}{|c|l|l|l|}
\hline & ALL & PRE & POST \\
& $01 / 01 / 1999$ & $01 / 01 / 1999$ & $01 / 01 / 2009$ \\
& $13 / 03 / 2015$ & $31 / 12 / 2008$ & $13 / 03 / 2015$ \\
\hline$\alpha$ & 0.066 & 0.065 & 1.634 \\
\hline$R$ & 14749.1 & 846.7 & 320696.1 \\
\hline
\end{tabular}

Table 3: Estimated parameter $\alpha$ of the Vašíček model and related Likelihood test statistics

\begin{tabular}{|l|c|c|}
\hline & TTC & PIT \\
\hline Issuer & $0.21 \%$ & $1.63 \%$ \\
\hline Depository & $0.32 \%$ & $1.92 \%$ \\
\hline
\end{tabular}

Table 4. Estimated default probability on annual basis 
Author 


\begin{tabular}{|c|c|c|c|c|c|c|c|c|c|c|c|}
\hline \multirow{5}{*}{$\begin{array}{l}\text { C } \\
\mathbf{O} \\
\mathbf{N} \\
\mathbf{V} \\
\text { E } \\
\mathbf{R} \\
\mathbf{T} \\
\mathbf{I} \\
\mathrm{B} \\
\mathrm{L} \\
\mathrm{E} \\
\mathrm{S}\end{array}$} & \multirow{3}{*}{$\begin{array}{l}\text { Defuault Probability } \\
\text { (PD) Issuer and } \\
\text { Depository }\end{array}$} & \multicolumn{4}{|c|}{ COUPON without any short-term rate process hypothesis } & \multicolumn{6}{|c|}{ COUPON with Vasicek short-term rate process hypothesis } \\
\hline & & \multicolumn{2}{|c|}{$\begin{array}{l}\text { Dividend Payment } \\
\text { probability: TTC hypothesis } \\
(90 \%)\end{array}$} & \multicolumn{2}{|c|}{$\begin{array}{l}\text { Dividend Payment } \\
\text { probability: worst scenario } \\
(75 \%)\end{array}$} & \multicolumn{3}{|c|}{$\begin{array}{l}\text { Dividend Payment probability: TTC } \\
\text { hypothesis }(90 \%)\end{array}$} & \multicolumn{3}{|c|}{$\begin{array}{l}\text { Dividend Payment probability: worst } \\
\text { scenario }(75 \%)\end{array}$} \\
\hline & & $\begin{array}{l}\text { Euribor3m } \\
\text { implicit }\end{array}$ & $\begin{array}{l}\text { Euribor3m } \\
\text { flat } 0.1 \%\end{array}$ & $\begin{array}{l}\text { Euribor3m } \\
\text { implicit }\end{array}$ & $\begin{array}{l}\text { Euribor3m } \\
\text { flat } 0.1 \%\end{array}$ & PRE & POST & ALL & PRE & POST & $\overline{A L L}$ \\
\hline & $\begin{array}{l}\text { Real/historical (TTC) } \\
\text { Issuer }=0.21 \%, \\
\text { Depository }=0.32 \%\end{array}$ & $1,514,321$ & $1,409,593$ & $1,277,085$ & $1,188,745$ & $1,501,807$ & $1,237,527$ & $1,168,953$ & $1,269,502$ & $1,048,693$ & 985,974 \\
\hline & $\begin{array}{l}\text { Risk neutral/implicit } \\
(\mathrm{PIT}) \\
\text { Issuer }=1.63 \% \\
\text { Depository }=1.92 \%\end{array}$ & 941,236 & 901,318 & $\begin{array}{l}798,968 \\
\end{array}$ & 756,108 & 934,905 & 796,068 & 746,755 & 794,244 & 660,952 & 625,809 \\
\hline
\end{tabular}

Table 5. Cashes estimated actual value (EUR) 
Copyright (C) 200x Inderscience Enterprises Ltd. 